\title{
Fractionated Gamma Knife Radiosurgery as Initial Treatment for Large Skull Base Meningioma
}

\author{
Hye Ran Park ${ }^{1}$, Jae Meen Lee ${ }^{2}$, Kwang-Woo Park ${ }^{3}$, Jung Hoon Kim³ ${ }^{3}$ Sang Soon Jeong ${ }^{3}$, \\ Jin Wook Kim ${ }^{3}$, Hyun-Tai Chung ${ }^{3}$, Dong Gyu Kim ${ }^{3}$ and Sun Ha Paek ${ }^{3,4,5 *}$ \\ ${ }^{1}$ Department of Neurosurgery, Soonchunhyang University Seoul Hospital, Seoul 04401, \\ ${ }^{2}$ Department of Neurosurgery, Pusan National University Hospital, Busan 49241, ${ }^{3}$ Department of Neurosurgery, \\ Seoul National University Hospital, Seoul 03080, ${ }^{4}$ Cancer Research Institute, Seoul National University, Seoul 03080, \\ ${ }^{5}$ Ischemia Hypoxia Disease Institute, Seoul National University, Seoul 03080, Korea
}

\begin{abstract}
We present our experience on the hypofractionated Gamma Knife radiosurgery (FGKS) for large skull base meningioma as an initial treatment. We retrospectively reviewed 23 patients with large skull base meningioma $\geq 10 \mathrm{~cm}^{3}$ who underwent FGKS as the initial treatment option. The mean volume of tumors prior to radiosurgery was $21.2 \pm 15.63 \mathrm{~cm}^{3}$ (range, 10.09 71.42). The median total margin dose and marginal dose per fraction were $18 \mathrm{~Gy}$ (range, 15 20) and $6 \mathrm{~Gy}$ (range, 5 6), respectively. Patients underwent three or four fractionations in consecutive days with the same Leksell ${ }^{\circledast}$ frame. The mean follow-up duration was 38 months (range, 17 78). There was no mortality. At the last follow-up, the tumor volume was stationary in 15 patients (65.2\%) and had decreased in 8 patients (34.8\%). Six patients who had cranial neuropathy at the time of FGKS showed improvement at the last clinical follow-up. Following FGKS, 4 patients (17\%) had new cranial neuropathy. The trigeminal neuropathy was the most common and all were transient. The mean Karnofsky Performance Status score at pre-FGKS and the last clinical follow-up was 97.0 \pm 10.4 points (median, 100)

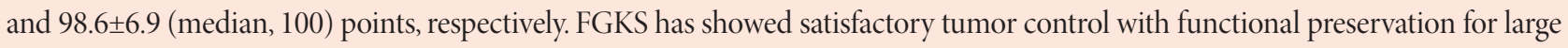
skull base meningiomas. Further prospective studies of large cohorts with long term follow-up are required to clarify the efficacy in the tumor control and functional outcome as well as radiation toxicity.
\end{abstract}

Key words: Gamma Knife Radiosurgery, Dose Hypofractionation, Meningioma, Skull Base, Stereotactic Radiosurgery

\section{INTRODUCTION}

Meningioma originates from meningothelial cells of the arachnoid and is usually attached to the dura. It accounts for approximately $13 \% \sim 30 \%$ of primary intracranial tumor in adults.

Received March 26, 2018, Revised May 2,2018,

Accepted May 24, 2018

* To whom correspondence should be addressed. TEL: 82-2-2072-3993, FAX: 82-2-744-8459 e-mail:paeksh@snu.ac.kr
About $20 \% \sim 30 \%$ of meningioma occurs in the skull base. Most are benign and slow-growing tumors, and immediate intervention is not often needed [1-3]. However, if there is a clear tumor progression or any progressive or newly developed clinical symptoms, treatment is indicated. The goal of meningioma treatment is to minimize tumor progression or recurrence with low treatmentassociated morbidity. Although the mainstay of meningioma treatment is surgical resection, many patients with skull base meningioma often fail to achieve complete resection without significant neurologic deficit due to the frequent involvement of cavernous sinus or cranial nerve, or close proximity to optic nerve or chiasm
Copyright $($ C) Experimental Neurobiology 2018. www.enjournal.org
This is an Open Access article distributed under the terms of the Creative Commons Attribution Non-Commercial License (http://creativecommons.org/licenses/by-nc/4.0) which permits unrestricted non-commercial use, distribution, and reproduction in any medium, provided the original work is properly cited. 
[4-7]. The progression rate after incomplete resection of Simpson grade III or higher has been reported to be $30 \%$ at 5 years, $60 \%$ at 10 years, and $90 \%$ at 15 years [8-10]. Despite the recent advances in microsurgical technique, the morbidity and mortality after surgical resection of skull base meningioma is still high [11-13].

Radiotherapy (RT) is safe and effective as a primary treatment for inoperable meningioma or adjuvant treatment for recurrent tumor after surgical resection $[14,15]$. Conventional radiotherapy has shown a 10 -year tumor control rate exceeding $80 \%$ in large residual tumors or progressive growing masses [16, 17]. Fractionated stereotactic RT (FSRT) was developed to reduce the high radiation dose administered to the surrounding normal brain tissue. FSRT has a similar therapeutic outcome compared to conventional RT $[18,19]$. For smaller tumors, stereotactic radiosurgery (SRS) such as a linear accelerator or Gamma Knife radiosurgery (GKS), has equivalent local control rates and acceptable toxicity [20-23]. However, SRS is limited in effectiveness for tumors close to the critical structures or tumors having a large volume, because of the radiosensitivity of these structures to a single large radiation dose. Multi-session or fractionated radiosurgery can be attractive and noninvasive treatment options for large residual or recurrent, inoperable skull base meningiomas. Hypofractionated radiosurgery can reduce the risk of late side effects because it allows normal tissue repair between fractions while delivering high dose per fraction [24]. In addition, reoxygenation and reassortment between fractions can improve tumor control by increasing cell kill. Colombo et al. [25] reported their experience of hypofractionated radiosurgery for meningioma patients who were unable to have single-session SRS using a Cyberknife with up to five fractionations. The authors reported a satisfactory tumor volume control rate of approximately $96.5 \%$ during the median 30-month followup period. However, as far as we know, there are few reports of fractionated radiosurgery for meningioma using GKS. While the Cyberknife and other linear accelerator-based systems perform multisession radiosurgery with $80 \%$ prescription isodose, the GKS Extend can give a higher maximum and cumulative radiation dose to the treatment volume using 50\% isodose line [26]. We present our experience on the feasibility, neurological outcome, tumor control, and complication rate of hypofractionated GKS (FGKS) in consecutive days with the same Leksell ${ }^{\circledR}$ frame for large-sized skull base meningioma.

\section{MATERIALS AND METHODS}

\section{Patient population}

A review of our records revealed 149 consecutive patients with intracranial meningioma, who underwent FGKS at Seoul Na- tional University Hospital (SNUH) between November 2009 and June 2015. The International Review Board of SNUH approved this retrospective study and waived the requirement for informed consent considering the retrospective design of the study. FGKS was considered for the large skull base tumors adjacent to eloquent area or critical organs. The clinical symptoms were not severe in a large number of patients, and it was difficult to try surgical resection with high morbidity rates.

Of the 149 patients, 52 had large skull base meningioma $\geq 10$ $\mathrm{cm}^{3}$. To clarify the efficacy of FGKS as an initial treatment option for large skull base meningioma, we excluded 27 patients who had previous surgical resection with or without adjuvant radiation, and 2 patients with prior radiosurgery. The remaining 23 patients

Table 1. Baseline characteristics of 23 patients with large skull base meningiomas treated with fractionated Gamma knife radiosurgery

\begin{tabular}{|c|c|}
\hline Parameters & Values \\
\hline Mean age, range (years) & $65(54 \sim 80)$ \\
\hline Gender: male/female & $6(26 \%) / 17(74 \%)$ \\
\hline \multicolumn{2}{|l|}{ Pre-FGKS clinical manifestations } \\
\hline Headache & $5(22 \%)$ \\
\hline Dizziness & $4(17 \%)$ \\
\hline Visual field defect & $3(13 \%)$ \\
\hline Seizure & $1(4 \%)$ \\
\hline \multicolumn{2}{|l|}{ Cranial nerve deficit } \\
\hline III/IV/VI & $1(4 \%)$ \\
\hline $\mathrm{V}$ & $2(9 \%)$ \\
\hline VII & 0 \\
\hline VIII & $1(4 \%)$ \\
\hline IX/X & 0 \\
\hline XI & 0 \\
\hline XII & 0 \\
\hline Weakness & $1(4 \%)$ \\
\hline Cognitive impairment & 0 \\
\hline \multicolumn{2}{|l|}{ Location } \\
\hline \multicolumn{2}{|l|}{ Middle } \\
\hline Parasellar & $2(9 \%)$ \\
\hline Sphenoid ridge & $4(17 \%)$ \\
\hline Cavernous sinus & $5(22 \%)$ \\
\hline \multicolumn{2}{|l|}{ Posterior } \\
\hline Cerebellopontine angle & $9(39 \%)$ \\
\hline Petroclival & $2(9 \%)$ \\
\hline Tentorial & $1(4 \%)$ \\
\hline \multicolumn{2}{|l|}{ Tumor volume } \\
\hline Mean \pm SD $\left(\mathrm{cm}^{3}\right)$ & $21.63 \pm 15.46$ \\
\hline Range $\left(\mathrm{cm}^{3}\right)$ & $10.09 \sim 71.42$ \\
\hline $10 \sim 20 \mathrm{~cm}^{3}$ & $15(65 \%)$ \\
\hline $20 \sim 30 \mathrm{~cm}^{3}$ & $5(22 \%)$ \\
\hline $30 \sim 40 \mathrm{~cm}^{3}$ & $1(4 \%)$ \\
\hline$\geq 40 \mathrm{~cm}^{3}$ & $2(9 \%)$ \\
\hline \multicolumn{2}{|l|}{ Maximum tumor diameter (mm) } \\
\hline Mean \pm SD & $31.31 \pm 8.38$ \\
\hline Range & $13.43 \sim 52.79$ \\
\hline Mean clinical follow-up duration, range (months) & $38(17 \sim 78)$ \\
\hline
\end{tabular}


were included. The clinical characteristics of the patients are summarized in Table 1. Single lesion was noted in 20 patients and 3 patients had multiple lesions.

Of the 23 patients with large skull base meningiomas, 6 were male $(26 \%)$ and 17 were female $(74 \%)$, with a mean age of 65 years (range 54 80 years). All patients were diagnosed as meningioma based on clinical and characteristic radiologic findings by neurosurgeons and neuroradiologists. Alteration in function of cranial nerves (CNs) III, IV, V, or VI was the most common neurological deficit on presentation. The mean volume of tumors prior to radiosurgery was $21.63 \pm 15.46 \mathrm{~cm}^{3}$ (median, $15.1 \mathrm{~cm}^{3}$; range, $\left.10.09 \sim 71.42 \mathrm{~cm}^{3}\right)$.

\section{Radiosurgical technique}

Gamma knife radiosurgery was performed with the Leksell Gamma Knife model Perfexion (Elekta Instrument AB, Stockholm, Sweden) using Leksell Gamma Plan (Elekta, Stockholm, Sweden). Gadolinium-enhanced T1-weighted and/or T2-weighted magnetic resonance imaging (MRI) was done with all patients, with a thin slice thickness of 1 to $1.5 \mathrm{~mm}$. MRI data were digitized and transferred to the treatment planning system (Leksell Gamma Plan) through a picture archiving and communication system. GKRS planning was performed using axial images supplemented with reconstructed coronal and sagittal MRI. The radiosurgical parameters are presented in Table 2 . The median total margin dose and marginal dose per fraction were $18 \mathrm{~Gy}$ (range, 15 20 Gy) and 6 Gy (range, 5 6 Gy), respectively. Patients underwent three or four fractionations in consecutive days with the same Leksell ${ }^{\circledR}$ frame. Tumor volumes were measured in follow-up images using the Osiris program (version 4.8; Service of Medical Informatics, Geneva University Hospital, Geneva, Switzerland), which allows the measurement of three-dimensional volume on the basis of MR images.

Table 2. Fractionated Gamma knife radiosurgery treatment parameters

\begin{tabular}{lc}
\hline \multicolumn{1}{c}{ Parameters } & Values \\
\hline Median total marginal dose, range (Gy) & $18,15 \sim 20$ \\
Median marginal dose per fraction, range (Gy) & $6,5 \sim 6$ \\
Median maximum dose, range (Gy) & $12.1,10 \sim 68.6$ \\
No. of fractionation, $\mathrm{n}(\%)$ & \\
3 & $21(91 \%)$ \\
4 & $2(9 \%)$ \\
Median isodose line (\%) & 50 \\
Median no. of shot, range & $27,11 \sim 49$ \\
Fractionation schedule, $\mathrm{n}(\%)$ & \\
6 Gy $\times 3$ & $18(78 \%)$ \\
$5 \mathrm{~Gy} \times 3$ & $3(13 \%)$ \\
$5 \mathrm{~Gy} \times 4$ & $2(9 \%)$ \\
\hline
\end{tabular}

\section{Radiological and clinical follow-up}

Most patients had follow-up clinical evaluations 1, 3, 6, and 12 months after GKRS and then annually until 5 years after radiosurgery and every 2 months thereafter. At each follow-up visit, a neurological examination was performed to evaluate for new neurological deficits, and neuroimaging studies were reviewed to assess tumor response by both a neurosurgeon and neuroradiologist. Radiographic change of tumor volume was defined as decrease ( $\leq 85 \%$ of the initial volume), stable ( $85 \% \sim 115 \%$ of the initial volume), or increase ( $\geq 115 \%$ of the initial volume). The presence of peritumoral edema and radiation necrosis was defined as a newly appeared high signal in T2-weighted image and a loss of contrast enhancement in the center of the tumor, respectively. Clinically, the improvement or deterioration of pre-existing symptoms and the presence of newly appeared neurological symptoms were investigated. Favorable outcome was defined as tumor volume decrease or stable with no deterioration of neurologic symptoms or newly developed neurologic deficit, and unfavorable outcome was defined as increased tumor volume or exacerbation of neurologic symptoms.

\section{Statistical analyses}

Overall survival and actuarial local tumor control rates were calculated using the Kaplan-Meier methods. The Cox proportional hazard model with the backward stepwise method was used for multivariate analyses and the results are presented as the hazard ratio (HR) and 95\% confidence intervals (CI) as appropriate. The following dependent variables were assessed in univariate and multivariate analysis: tumor-free progression, worsening or new decline in neurological function, and favorable outcome. Clinical covariates predicting new or worsening decline in neurological function with a univariate $\mathrm{p}$ value $<0.20$ were included in multivariable logistic regression analysis. Clinical covariates predicting unfavorable outcome with a univariate $p$ value $<0.20$ were included in multivariable logistic regression analysis. All the statistical analyses were performed with commercially available software (SPSS version 18.0; SPSS Inc., Chicago, IL). Statistical significance was accepted at $\mathrm{p}<0.05$ level.

\section{RESULTS}

\section{Radiologic outcome}

The mean follow-up duration was 38 months (range, 17 78). At the last follow-up, the tumor volume was stationary in 15 patients (65.2\%), and decreased in 8 patients (34.8\%). No patient experienced failure to control tumor volume. The mean tumor volume decreased significantly from $21.63 \pm 15.46 \mathrm{~cm}^{3}$ to $19.75 \pm 15.70 \mathrm{~cm}^{3}$ 
$(\mathrm{p}=0.000)$. Fig. 1 shows the tumor volume change in all patients. One patient (4.3\%) had a peritumoral edema prior to FGKS. Following radiosurgery, 2 patients $(9.0 \%)$ had new or worsening edema within 18 months of treatment. Of the 2 , one patient had progression of preexisting edema and the other patient developed edema following radiosurgery. There was no symptomatic edema requiring further management and edema spontaneously improved without steroid in both patients. Central necrosis was detected in 2 patients (8.7\%). Neither experienced tumor recurrence or secondary malignancy after radiosurgery.

\section{Clinical outcome}

Before FGKS, 6 patients (26\%) complained of cranial neuropathy and 17 patients (74\%) had no cranial neuropathy. The most common cranial neuropathy was visual field defect (3 patients, $13 \%$ ), followed by trigeminal neuralgia ( 2 patients, $8.7 \%$ ), hearing difficulty ( 1 patients, $4.3 \%$ ), and diplopia ( 1 patients, $4.3 \%$ ). All 6 patients with cranial neuropathy at the time of FGKS were improved at the last clinical follow-up. Following FGKS, 5 patients (21.7\%) had new cranial neuropathy. In all cases, the neuropathy was transient, and included trigeminal neuralgia/facial numbness in 3 patients (18\%), dysphagia in one patient (6\%), and visual dimness in one patient $(6 \%)$. Descriptions of clinical status are presented in Table 3. The most common newly developed cranial neuropathy during the follow-up period was trigeminal nerve deficit. Permanent cranial neuropathy did not occur. We did not experience any vascular injury of brainstem ischemia caused by radiosurgery.

Other pre-FGKS clinical symptoms were headache (5 patients, $21.7 \%$ ), dizziness (4 patients, 17.4\%), seizure (one patient, $4.3 \%$ ), and weakness (one patient, $4.3 \%$ ). Three patients with headache, seizure, and weakness remained unchanged, but the other patients' symptoms improved during the follow-up period (Table 3 ).

Of the 23 patients, 9 were followed up with continuous basal hormone test and visual field test from at the time of FGKS over the follow-up period. Of them, one patient showed thyroid stimulating hormone (TSH) depletion in the laboratory finding without associated clinical symptoms. The patient has been under followup without hormone replacement treatment. One patient revealed a central visual field defect after 1 month after FGKS, but he recovered spontaneously after 5 months.

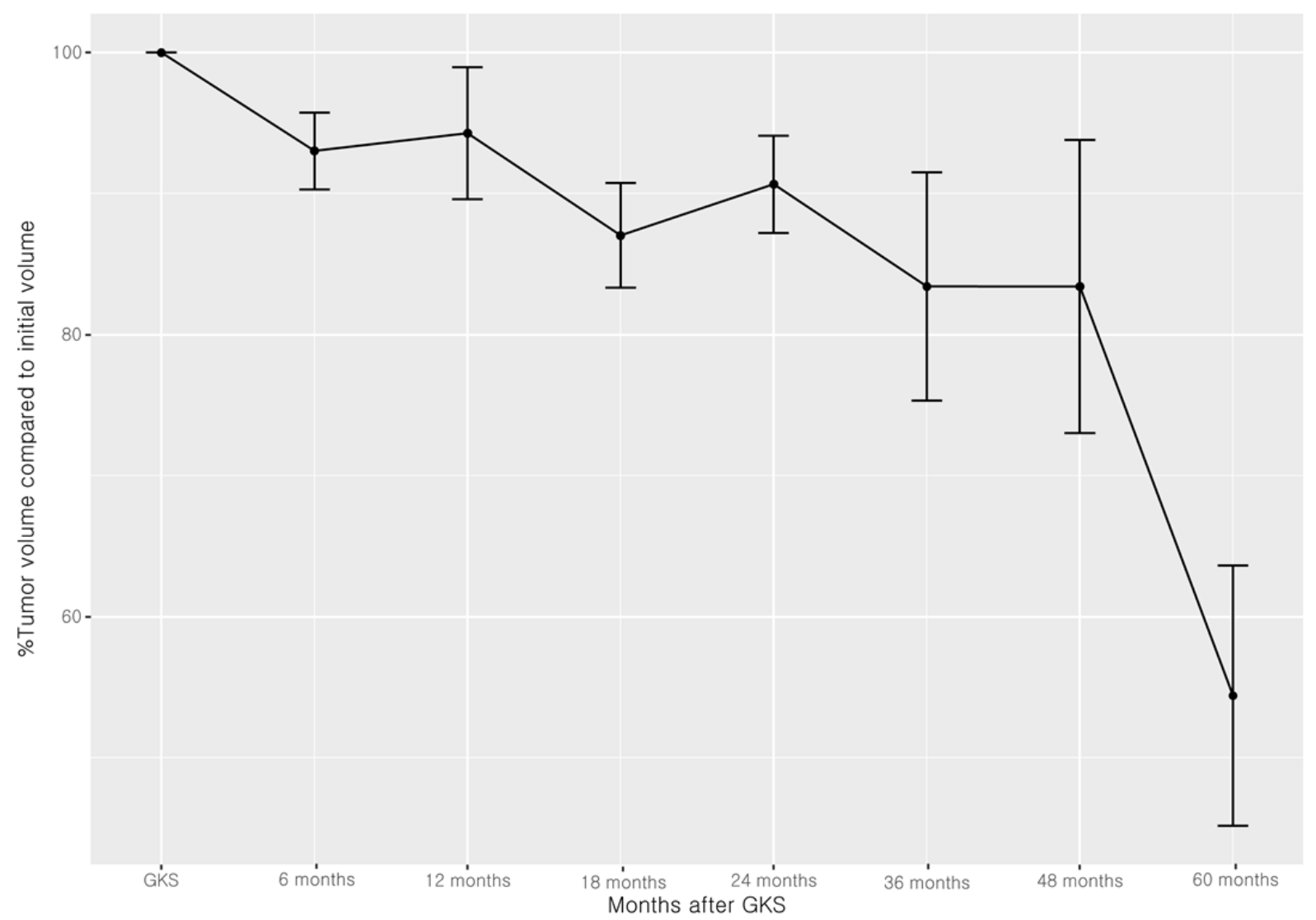

Fig. 1. Tumor volume change in all patients. At the last follow-up, the tumor volume was stationary in 15 patients (65.2\%), and decreased in 8 patients $(34.8 \%)$. 
Table 3. Cranial nerve deficits and other neurologic deficits before radiosurgery and changes after radiosurgery of 23 patients with large skull base meningiomas treated with FGKS

\begin{tabular}{lcccc}
\hline \multirow{2}{*}{ Clinical manifestations } & Baseline & \multicolumn{2}{c}{ Last follow-up } & New deficits \\
\cline { 3 - 4 } & 5 & Improvement & Stationary & Aggravation \\
Headache & 4 & 4 & 1 \\
Dizziness & 1 & & 1 \\
Weakness & 1 & & \\
Hypopituitarism & & 3 & 1 \\
Seizure & 3 & & \\
CN deficit & 1 & 2 & \\
II & 2 & 1 & \\
III/IV/VI & 1 & & \\
V & & & \\
VIII & & & \\
XII & & & \\
\hline
\end{tabular}

*Subclnical level.

The mean Karnofsky Performance Status score at pre-FGKS and the last clinical follow-up was $97.0 \pm 10.4$ points (median, 100) and $98.6 \pm 6.9$ (median, 100) points, respectively. To the last follow-up, 22 patients maintained their daily living and job activities at the same level after FGKS. One patient who could not stand due to associated hydrocephalus before FGKS improved to walk with assist after FGKS followed by a ventriculoperitoneal (VP) shunt.

\section{Complications and further treatments following FGKS}

One patient (4\%) underwent VP shunt surgery. This patient with cerebellopontine angle meningioma complained of voiding difficulty and gait disturbance, and the symptoms related with hydrocephalus improved after VP shunt which was performed at post-FGKS 5 months. There was no mortality during the followup period.

\section{Overall outcome}

We defined favorable outcome as no tumor progression and no new or developed neurologic deficit. There was no patient with tumor progression, but 5 patients (21.7\%) experienced neurological deficit, which is transient or permanent, were classified as unfavorable outcome group. The remaining 18 patients (78.2\%) were classified as favorable outcome group. Table 4 represents an analysis of factors that predict an occurrence of unfavorable outcome. Factors including age older than 70 years, male gender, tumor location, newly developed peritumoral edema or central necrosis, total marginal dose, and tumor volume were analyzed to figure out the effect on unfavorable outcome. There were no statistically significant factors in univariate analysis, which might be caused by too small cohort.
Table 4. Predictors of unfavorable outcome

\begin{tabular}{lccc}
\hline \multirow{2}{*}{\multicolumn{1}{c}{ Variables }} & \multicolumn{3}{c}{ Unfavorable outcome } \\
\cline { 2 - 4 } & \multicolumn{3}{c}{ Univariate } \\
\cline { 2 - 4 } & HR & p value & $\mathbf{9 5 \% ~ C I ~}$ \\
\hline Age $>70 \mathrm{y}$ & 2.33 & 0.9963 & \\
Male gender & 0.67 & 0.6931 & $0.24 \sim 19.82$ \\
Middle fossa location & 1.50 & 0.6931 & $0.20 \sim 13.59$ \\
Posterior fossa location & & 0.9953 & \\
Peritumoral edema & 4.25 & 0.3410 & $0.15 \sim 124.90$ \\
Central necrosis & & 0.9963 & \\
Total marginal dose $\geq 18$ Gy & & 0.7822 & $0.15 \sim 10.36$ \\
Tumor volume $\geq 20 \mathrm{~cm}^{3}$ & 1.33 & &
\end{tabular}

\section{Case presentation}

A 68-year-old man without a medical history was referred for the management of incidentally found petroclival meningioma. At the time of admission, the patient did not have any specific symptom or cranial neuropathy. On MRI, a dural based enhancing mass with iso-signal on T1-weighted and high signal intensity T2-weighted was found in the petroclival region. The volume of tumor mass was $17.8 \mathrm{~cm}^{3}$. FGKS was performed for 3 consecutive days considering the age of patient, large tumor volume, and petroclival location. Radiosurgical parameters were: total marginal dose $18 \mathrm{~Gy}$ in three fractionations, isodose line 50\%, and shot 33 . At 6 months after FGKS, the patient complained of transient facial numbness but the symptom disappeared spontaneously without any special management. On MRI at 6 months post-FGKS, decreased size of tumor of $9.7 \mathrm{~cm}^{3}$ with decreased central enhancement, suggesting necrosis due to radiation, was identified. Fig. 2 shows serial MRI data. The basal hormone test and visual field test performed every year after FGKS remained normal. Tumor volume remained reduced and was $8.6 \mathrm{~cm}^{3}$ at the last follow-up at 


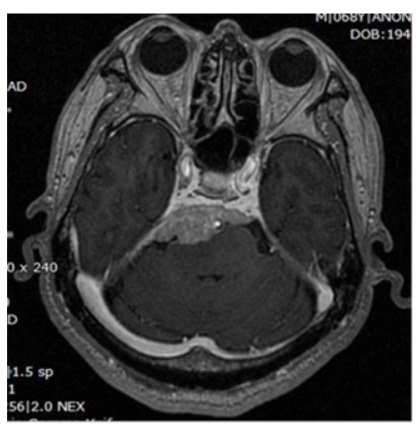

Pre-GKS

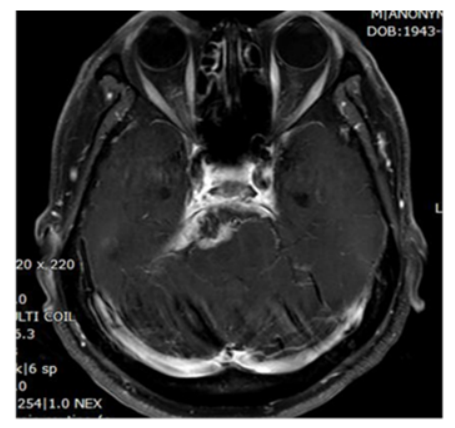

6 months

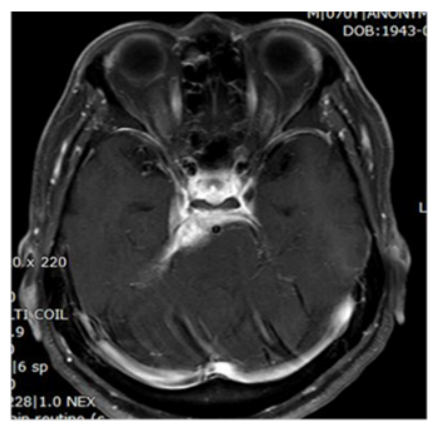

18 months

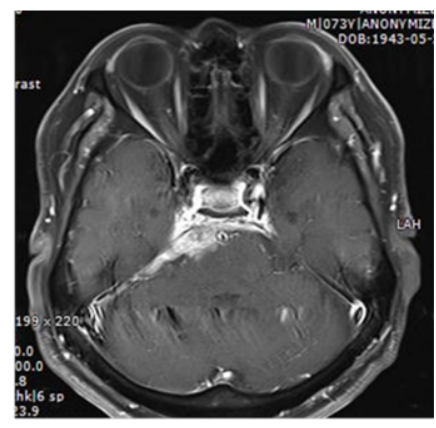

54 months

Fig. 2. Serial MRI of the patient who received hypofractionated Gamma knife radiosurgery (FGKS) for incidentally found petroclival meningioma. The initial volume of tumor mass was $17.8 \mathrm{~cm}^{3}$. FGKS was performed for 3 consecutive days. Radiosurgical parameters were: total marginal dose 18 Gy in 3 fractionation, isodose line 50\%, and shot 33. At 6 months after FGKS, the patient complained of transient facial numbness but the symptom disappeared spontaneously without any special management. On MRI at post-FGKS 6 months, decreased size of tumor of $9.7 \mathrm{~cm}^{3}$ with decreased central enhancement, suggesting necrosis due to radiation, was identified.

54 month, which was $48.31 \%$ decrease compared to initial tumor volume.

\section{DISCUSSION}

The goal of SRS in meningioma is local tumor control and preservation of neurological function [27]. SRS has shown satisfactory outcome with $\geq 90 \%$ tumor growth control rates $[25,28,29]$. In a long-term study of GKS with mean marginal dose of 14 Gy for 972 patients (1,045 tumors), the 10 -year local control rate was $91 \%$, $50 \%$, and $17 \%$ in WHO grade I, II, and III, respectively [30, 31]. A Mayo Clinic follow-up study of 190 patients with 206 meningiomas treated by median prescription dose $16 \mathrm{~Gy}$ found the 5- and 7 -year survival rate of $94 \%$ and $92 \%$. In SRS for meningioma, the effect of local control highly depends on radiation dose, and single fraction dose $\leq 15$ Gy is less effective $[32,33]$.

GKS is a radiosurgery usually performed in a single session. However, lesions adjacent to radiation-sensitive critical structures, such as the optic pathway, increase the risk of traditional singlesession GKS. Large-sized lesions also increase the risk [34]. Currently, the concept of radiosurgery has been extended up to five fractionations. More studies on fractionation have been recently done, reflecting the interest in avoiding unwanted radiation to adjacent radio-sensitive structures while giving high-dose radiation to the target [26, 35-39]. Fractionation is a method of delivering higher cumulative radiation dose to target while minimizing damage to normal tissues. It is hypothesized that sublethal damage is rapidly repaired in normal tissue $[34,40]$.

Hypofractionated radiosurgery has shown similar efficacy and treatment related toxicity, as reported in single-session SRS. Studies on FGKS have include the use of 20 Gy in three to five fractions
[41] and 25 Gy in five fractions [42]. Both studies usually targeted benign neoplasms adjacent to the optic pathway, and neither had visual toxicity. Despite the fact that fractionation reduces unwanted radiation to surrounding tissue, higher doses are required to achieve the same dose effect due to DNS repair and cell repopulation between fractions [43]. While the Cyberknife and other linear accelerator-based systems perform multisession radiosurgery with $80 \%$ prescription isodose, the GKS Extend system can give a higher maximum and cumulative radiation dose to the treatment volume using 50\% isodose line [26]. Previous studies indicated that higher maximum dose and dose heterogeneity of target may play an important role in a highly beneficial radiobiologic pathway, especially in late-responding tissue such as benign tumors, resulting in delayed vascular response $[44,45]$. The dose heterogeneity of multisession GKS with 50\% isodose line may be beneficial in the treatment of solid neoplasm, unlike the linear-accelerator based system, which is 80\% 90\% isodose line [46]. FGKS will broaden the indication of intracranial radiosurgery that can be treated with GKS.

Skull base meningiomas have a poorer outcome of single-session GKS than meningiomas located in other sites. Studies published on long-term efficacy of radiosurgery for skull base meningioma have reported tumor control rates of $89 \%$ to $98 \%$ and acceptable complication rates of $4 \%$ to $14 \%$ [47-51]. Our group reported a long-term outcome of single-session GKS for skull base meningioma [52]. The 5-year actuarial tumor control rate was $90.2 \%$ and unfavorable outcome of cranial neuropathy occurred in $15.9 \%$. The improvement of cranial neuropathy was $45.1 \%$, especially, the meningioma located at cavernous sinus showed a high improvement rate even at low marginal dose of $12 \mathrm{~Gy}$.

There are several reports of FSRT for large skull base meningio- 
mas. Debus et al. [18] reported their experiences about FSRT for 189 patients with a mean tumor volume of $52.5 \mathrm{~cm}^{3}$. The median radiation dose was 56.8 Gy and the mean follow-up duration was 35 months. The actuarial tumor control rate of WHO grade I meningiomas was $97 \%$ at 5 years and $96 \%$ at 10 years. Clinical significant treatment-induced toxicity was 1.6\%. Minniti et al. [19] reported obtained similar outcomes after FSRT for 52 large skull base meningiomas. The median gross tumor volume (GTV) was $35.4 \mathrm{~cm}^{3}$, and radiotherapy was performed in 30 daily fractions over 6 weeks to a total dose of 50 Gy. During the median follow-up period of 42 months, the progression-free survival (PFS) rate was $96 \%$ and $93 \%$ at 3 and 5 years, respectively. Clinically significant late neurological toxicity was reported in $5.5 \%$ of the patients.

Bria et al. [53] reported the results of hypofractionated radiosurgery using the CyberKnife for 73 meningiomas. Local failure occurred in 11 cases, and the 1-year survival rate was $95 \%, 71 \%$, and $9 \%$ in WHO grade I, II, and III, respectively. Tumor-related symptoms improved in $60 \%$ of cases. Satisfactory outcome on tumor control with similar toxicity rates compared to single-session GKS were evident in this study and previously reported studies.

Starke et al. [54] reported their single-session GKS experiences for 75 large skull base meningiomas with a mean tumor volume of $14.1 \mathrm{~cm}^{3}$. The mean follow-up duration was 6.5 years, and the actuarial PFS rate was 90.3\% (3-year), 88.6\% (5-year), and 77.2\% (10-year). The neurological function deteriorated in $17 \%$ of the patients. To overcome the limitations of single-session GKS, few authors have tried multi-session GKS for skull base meningiomas. Iwai et al. [55] performed two-stage GKS for large petroclival and cavernous sinus meningiomas with a median prescription dose of 9 Gy per session. The mean initial tumor volume was $16.8 \mathrm{~cm}^{3}$. After median follow-up duration of 39 months, 6 patients (86\%) obtained local control, and 3 had symptom improvement. Tumor progression occurred in only one person. There was no toxicity associated with treatment. There was also a study of volume-staged GKS in large skull base meningiomas with mean volume of 13.2 $\mathrm{cm}^{3}$ [56]. The tumor margin dose at stage I and II was $13.5 \mathrm{~Gy}$ and 9 Gy, respectively. Although only 4 patients were included in the study, after the median follow-up period of 100.5 months, all 4 patients obtained tumor control and all neurological deficits that existed before GKS were improved.

The Stanford group reviewed the outcome of fractionated SRS using the Cyberknife for large benign skull base tumors, including 21 meningiomas [39]. For 34 large benign tumors with median tumor volume of $19.3 \mathrm{~cm}^{3}$, fractionated SRS with median prescription dose of $24 \mathrm{~Gy}$ was performed over two to five sessions. After 31 months of median follow-up period, fractionated SRS was effective and safe, with local control rate of $100 \%$ and symptom improvement rate of $21 \%$. About $11.7 \%$ of patients required glucocorticoids treatment due to transient neurological worsening, but there was no permanent deficit.

To our knowledge, two reports included FGKS experiences for large skull base meningioma. In the published reports, FGKS was primarily considered for the tumors difficult to surgically access or tumors expected to have high complication rates after single GKS. Large meningiomas located in convexity, falx, or parasagittal sinus were included, because of the concern about the occurrence of extensive peritumoral edema after single GKS. Tumors adjacent to eloquent area or critical organs were also candidates for FGKS. Surgically inaccessible skull base meningiomas also became indications for FGKS. McTyre et al. [57] included 15 cases of meningioma $\geq 10 \mathrm{cc}$, attached to the optic pathway, or had previously undergone single-session GKS. Recently, a study was published on the comparison of single-session GKS $(\mathrm{n}=42)$ and FGKS $(\mathrm{n}=28)$ for meningiomas $\geq 10 \mathrm{~cm}^{3}$ [58]. The FGKS group also included 16 skull base meningiomas. The mean tumor volume of singlesession GKS and FGKS was $15.2 \mathrm{~cm}^{3}$ and $21 \mathrm{~cm}^{3}$, respectively. The FGKS group showed a higher overall 5-year tumor control rate than the single-session GKS group, without statistical significance (92.9\% vs $88.1 \%, \mathrm{p}=0.389)$.

In this study, the overall tumor control rate of skull base meningioma over mean follow-up duration of 38 months was 100\%. Although the mean follow-up duration was relatively short, FGKS revealed considerable tumor control rates compared to singlesession radiosurgery or conventional radiotherapy. Our group reported on the long-term outcome and growth rate of subtotally resected petroclival meningiomas in 2000 [59]. A total of 38 cases were followed for a mean of 47.5 months. The 5 -year PFS rate was $60 \%$ and the median PFS survival time was 66 months. Based on these results, we have proposed subtotal resection with or without radiation or radiosurgery for the treatment of skull base meningioma. However, with the development of the radiosurgery technique and the increase in safety and efficacy, we experienced better results after FGKS as an initial treatment rather than surgical resection for large skull base meningioma.

Single-session GKS or FGKS overcomes tumor cell redistribution or reoxygenation of hypoxic cells within the cell cycle. Dividing a single dose into fractions reduces damage to normal tissue by restoring sublethal damage between fractions and allows cell repopulation. However, FGKS should also be performed with consideration of normal tissue embedded within radiosurgical target. The effect of dose and fractionation on normal tissue can be assessed using a linear quadratic cell survival curve model. In this model, the $\alpha / \beta$ ratio reflects the cell response to changes in the radiation fraction size. Tissues with low $\alpha / \beta$ ratio, such as normal 
brain, are more sensitive to larger dose fractions. Benign tumors such as meningioma have a low $\alpha / \beta$ ratio $\leq 3$, so there is little benefit from fractionation and a single or hypofractionated regimen is preferred. Single session GKS for WHO grade I tumors has achieved a tumor control rate $\geq 90 \%$ using a dose of $14 \mathrm{~Gy}$ at $50 \%$ isodose line. In the FKGS for large skull base meningioma, we have tried a 3 or 4 fraction with a lower prescription dose, considering that the lesions are adjacent to the surrounding normal eloquent brain tissue or cranial nerve. The treatment dose given per fraction was determined to obtain the same biologically equivalent dose as in single session GKS using a BED calculation algorithm.

Symptomatic peritumoral edema has been reported on an average of 5\% 10\% after radiosurgery or conventional radiotherapy [31, 60-62]. Among the 23 patients who underwent FGKS, progression of the preexisting edema or newly developed edema was found in 2 patients, but there was no symptomatic edema. In previous studies, post-radiosurgical edema or necrosis was associated with tumor volume control [63], but we did not find any correlation between them in this study.

FKGS showed satisfactory results in clinical aspects, especially in facial pain. Two patients who had trigeminal neuralgia experienced a dramatic facial pain improvement after FGKS. This is consistent with previous findings that the fractionated approach is beneficial for tumor-associated trigeminal neuralgia [64-67]. After FGKS, there was no exacerbation of pre-existing cranial neuropathy, and 5 patients experienced newly developed cranial neuropathy but all of them was transient finding and improved spontaneously. We did not experience an occurrence of permanent neurologic deficit.

Our main concern was that whether the patients could tolerate the procedure well with the fixation of stereotactic frame for 3 or 4 consecutive days. All patients tolerated the pain and headache. Another concern about the movement of target in each fraction was resolved with the use of scout images. Since the introduction of $\mathrm{ICON}^{\mathrm{TM}}$ in March 2016, more patients have received FGKS using mask immobilization comfortably without pain. Considering the similar tumor control rate to single-session GKS and the satisfactory clinical outcome, FGKS is expected to become useful in largesized skull base lesions including meningioma.

This study has some limitations resulting from its retrospective design and heterogeneous meningioma entities. We started the FGKS relatively recently and the follow-up duration is short. This study has no control group, and the comparison of efficacy and toxicity between single and fractionated GKS due to the small size of cohort. Another drawback is that there is no information on histology and proliferation indices, because radiosurgery was the initial treatment for meningioma diagnosed by imaging only.
Very little is known about the optimal dose and fractionation regimen. FGKS using mask immobilization has been growing, and optimal treatment regimen would be clarified. Despite performed using frame, this result reporting FGKS would be some help in implementing FGKS in the future. Further study about FGKS with follow-up exceeding 10 years and prospective design is necessary to identify the long-term results and radiation-toxicity.

We analyzed the clinical results of FGKS performed as an initial treatment option for large skull base meningioma. FGKS produced satisfactory tumor control with functional preservation for large skull base meningiomas. FGKS could be an alternative option for large skull base lesions such as meningiomas, while avoiding high risks or surgical resection. Further prospective studies of large cohorts with long-term follow-up are required to clarify the efficacy in the tumor control and functional outcome as well as radiation toxicity.

\section{ACKNOWLEDGEMENTS}

This study was supported by the Korea Healthcare Technology R\&D Project (grant no. HI11C21100200), funded by the Ministry of Health \& Welfare, Republic of Korea; the Industrial Strategic Technology Development Program (grant no. 10050154, Business Model Development for Personalized Medicine Based on Integrated Genome and Clinical Information) funded by the Ministry of Trade, Industry \& Energy (MI, Korea); the Original Technology Research Program for Brain Science through the National Research Foundation of Korea (NRF) funded by the Ministry of Education, Science and Technology (grant no. 2015M3C7A1028926); the Original Technology Research Program for Brain Science through the National Research Foundation of Korea (NRF) funded by the Ministry of Education, Science and Technology (grant no. 2017M3C7A1047392), and Soonchunhyang research fund.

There is no conflict of interest from any authors.

\section{REFERENCES}

1. Louis DN, Perry A, Reifenberger G, von Deimling A, Figarella-Branger D, Cavenee WK, Ohgaki H, Wiestler OD, Kleihues P, Ellison DW (2016) The 2016 World Health Organization classification of tumors of the central nervous system: a summary. Acta Neuropathol 131:803-820.

2. Claus EB, Bondy ML, Schildkraut JM, Wiemels JL, Wrensch M, Black PM (2005) Epidemiology of intracranial meningioma. Neurosurgery 57:1088-1095.

3. Rohringer M, Sutherland GR, Louw DF, Sima AA (1989) Incidence and clinicopathological features of meningioma. J 


\section{Neurosurg 71:665-672.}

4. Mirimanoff RO, Dosoretz DE, Linggood RM, Ojemann RG, Martuza RL (1985) Meningioma: analysis of recurrence and progression following neurosurgical resection. J Neurosurg 62:18-24.

5. Miralbell R, Linggood RM, de la Monte S, Convery K, Munzenrider JE, Mirimanoff RO (1992) The role of radiotherapy in the treatment of subtotally resected benign meningiomas. J Neurooncol 13:157-164.

6. O'Sullivan MG, van Loveren HR, Tew JM Jr (1997) The surgical resectability of meningiomas of the cavernous sinus. Neurosurgery 40:238-244.

7. Cusimano MD, Sekhar LN, Sen CN, Pomonis S, Wright DC, Biglan AW, Jannetta PJ (1995) The results of surgery for benign tumors of the cavernous sinus. Neurosurgery 37:1-9.

8. Marosi C, Hassler M, Roessler K, Reni M, Sant M, Mazza E, Vecht C (2008) Meningioma. Crit Rev Oncol Hematol 67:153-171.

9. Stafford SL, Perry A, Suman VJ, Meyer FB, Scheithauer BW, Lohse CM, Shaw EG (1998) Primarily resected meningiomas: outcome and prognostic factors in 581 Mayo Clinic patients, 1978 through 1988. Mayo Clin Proc 73:936-942.

10. Simpson D (1957) The recurrence of intracranial meningiomas after surgical treatment. J Neurol Neurosurg Psychiatry 20:22-39.

11. De Jesús O, Sekhar LN, Parikh HK, Wright DC, Wagner DP (1996) Long-term follow-up of patients with meningiomas involving the cavernous sinus: recurrence, progression, and quality of life. Neurosurgery 39:915-919.

12. Couldwell WT, Fukushima T, Giannotta SL, Weiss MH (1996) Petroclival meningiomas: surgical experience in 109 cases. J Neurosurg 84:20-28.

13. Natarajan SK, Sekhar LN, Schessel D, Morita A (2007) Petroclival meningiomas: multimodality treatment and outcomes at long-term follow-up. Neurosurgery 60:965-979.

14. Torres RC, Frighetto L, De Salles AA, Goss B, Medin P, Solberg T, Ford JM, Selch M (2003) Radiosurgery and stereotactic radiotherapy for intracranial meningiomas. Neurosurg Focus 14:e5.

15. Duma CM, Lunsford LD, Kondziolka D, Harsh GR 4th, Flickinger JC (1993) Stereotactic radiosurgery of cavernous sinus meningiomas as an addition or alternative to microsurgery. Neurosurgery 32:699-704.

16. Estall V, Fairfoul J, Jena R, Jefferies SJ, Burton KE, Burnet NG (2010) Skull base meningioma-comparison of intensitymodulated radiotherapy planning techniques using the moduleaf micro-multileaf collimator and helical tomotherapy.
Clin Oncol (R Coll Radiol) 22:179-184.

17. Minniti G, Amichetti M, Enrici RM (2009) Radiotherapy and radiosurgery for benign skull base meningiomas. Radiat Oncol 4:42.

18. Debus J, Wuendrich M, Pirzkall A, Hoess A, Schlegel W, Zuna I, Engenhart-Cabillic R, Wannenmacher M (2001) High efficacy of fractionated stereotactic radiotherapy of large base-of-skull meningiomas: long-term results. J Clin Oncol 19:3547-3553.

19. Minniti G, Clarke E, Cavallo L, Osti MF, Esposito V, Cantore G, Cappabianca P, Enrici RM (2011) Fractionated stereotactic conformal radiotherapy for large benign skull base meningiomas. Radiat Oncol 6:36.

20. Flannery TJ, Kano H, Lunsford LD, Sirin S, Tormenti M, Niranjan A, Flickinger JC, Kondziolka D (2010) Long-term control of petroclival meningiomas through radiosurgery. J Neurosurg 112:957-964.

21. Hamm K, Henzel M, Gross MW, Surber G, Kleinert G, Engenhart-Cabillic R (2008) Radiosurgery/stereotactic radiotherapy in the therapeutical concept for skull base meningiomas. Zentralbl Neurochir 69:14-21.

22. Nicolato A, Giorgetti P, Foroni R, Grigolato D, Pasquin IP, Zuffante M, Soda C, Tomassini A, Gerosa M (2005) Gamma knife radiosurgery in skull base meningiomas: a possible relationship between somatostatin receptor decrease and early neurological improvement without tumour shrinkage at short-term imaging follow-up. Acta Neurochir (Wien) 147:367-374.

23. Soisson ET, Tomé WA, Richards GM, Mehta MP (2006) Comparison of linac based fractionated stereotactic radiotherapy and tomotherapy treatment plans for skull-base tumors. Radiother Oncol 78:313-321.

24. Hall EJ, Giaccia AJ (2006) Radiobiology for the radiologist. Lippincott Williams \& Wilkins, Philadelphia, PA.

25. Colombo F, Casentini L, Cavedon C, Scalchi P, Cora S, Francescon P (2009) Cyberknife radiosurgery for benign meningiomas: short-term results in 199 patients. Neurosurgery 64 Suppl:A7-A13.

26. Kim JW, Im YS, Nam DH, Park K, Kim JH, Lee JI (2008) Preliminary report of multisession gamma knife radiosurgery for benign perioptic lesions: visual outcome in 22 patients. J Korean Neurosurg Soc 44:67-71.

27. Kondziolka D, Lunsford LD, Coffey RJ, Flickinger JC (1991) Stereotactic radiosurgery of meningiomas. J Neurosurg 74:552-559.

28. Duma CM, Lunsford LD, Kondziolka D, Harsh GR 4th, Flickinger JC (1993) Stereotactic radiosurgery of cavernous 
sinus meningiomas as an addition or alternative to microsurgery. Neurosurgery 32:699-704.

29. Rodolfo H, Eben A 3rd, Jay SL, Dennis CS, Patrick W, Maureen PF, Philip ES, Peter MB (1998) Results of linear accelerator-based radiosurgery for intracranial meningiomas. Neurosurgery 42:446-453.

30. Kondziolka D, Mathieu D, Lunsford LD, Martin JJ, Madhok R, Niranjan A, Flickinger JC (2008) Radiosurgery as definitive management of intracranial meningiomas. Neurosurgery 62:53-58.

31. Kondziolka D, Levy EI, Niranjan A, Flickinger JC, Lunsford LD (1999) Long-term outcomes after meningioma radiosurgery: physician and patient perspectives. J Neurosurg 91:4450.

32. Vogelbaum MA, Angelov L, Lee SY, Li L, Barnett GH, Suh JH (2006) Local control of brain metastases by stereotactic radiosurgery in relation to dose to the tumor margin. J Neurosurg 104:907-912.

33. Wiggenraad R, Verbeek-de Kanter A, Kal HB, Taphoorn M, Vissers T, Struikmans H (2011) Dose-effect relation in stereotactic radiotherapy for brain metastases. A systematic review. Radiother Oncol 98:292-297.

34. Flickinger JC (1989) An integrated logistic formula for prediction of complications from radiosurgery. Int J Radiat Oncol Biol Phys 17:879-885.

35. Adler JR Jr, Gibbs IC, Puataweepong P, Chang SD (2008) Visual field preservation after multisession cyberknife radiosurgery for perioptic lesions. Neurosurgery 62 Suppl 2:733-743.

36. Choi CY, Soltys SG, Gibbs IC, Harsh GR, Sakamoto GT, Patel DA, Lieberson RE, Chang SD, Adler JR (2011) Stereotactic radiosurgery of cranial nonvestibular schwannomas: results of single- and multisession radiosurgery. Neurosurgery 68:1200-1208.

37. Hansasuta A, Choi CY, Gibbs IC, Soltys SG, Tse VC, Lieberson RE, Hayden MG, Sakamoto GT, Harsh GR 4th, Adler JR Jr, Chang SD (2011) Multisession stereotactic radiosurgery for vestibular schwannomas: single-institution experience with 383 cases. Neurosurgery 69:1200-1209.

38. Marchetti M, Bianchi S, Milanesi I, Bergantin A, Bianchi L, Broggi G, Fariselli L (2011) Multisession radiosurgery for optic nerve sheath meningiomas--an effective option: preliminary results of a single-center experience. Neurosurgery 69:1116-1122.

39. Tuniz F, Soltys SG, Choi CY, Chang SD, Gibbs IC, Fischbein NJ, Adler JR Jr (2009) Multisession cyberknife stereotactic radiosurgery of large, benign cranial base tumors: preliminary study. Neurosurgery 65:898-907.
40. Ganz JC, Backlund EO, Thorsen FA (1993) The results of Gamma Knife surgery of meningiomas, related to size of tumor and dose. Stereotact Funct Neurosurg 61 Suppl 1:23-29.

41. Nguyen JH, Chen CJ, Lee CC, Yen CP, Xu Z, Schlesinger D, Sheehan JP (2014) Multisession gamma knife radiosurgery: a preliminary experience with a noninvasive, relocatable frame. World Neurosurg 82:1256-1263.

42. Devriendt D, De Smedt F, Glineur R, Massager N (2015) Five-fraction Gamma Knife radiosurgery using the Extend relocatable system for benign neoplasms close to optic pathways. Pract Radiat Oncol 5:e119-e125.

43. Ganz J (2012) Gamma knife surgery. Springer Science \& Business Media, New York, NY.

44. Linskey ME, Martinez AJ, Kondziolka D, Flickinger JC, Maitz AH, Whiteside T, Lunsford LD (1993) The radiobiology of human acoustic schwannoma xenografts after stereotactic radiosurgery evaluated in the subrenal capsule of athymic mice. J Neurosurg 78:645-653.

45. Pollock BE, Lunsford LD, Kondziolka D, Flickinger JC, Bissonette DJ, Kelsey SF, Jannetta PJ (1995) Outcome analysis of acoustic neuroma management: a comparison of microsurgery and stereotactic radiosurgery. Neurosurgery 36:215-224.

46. Kondziolka D, Somaza S, Comey C, Lunsford LD, Claassen D, Pandalai S, Maitz A, Flickinger JC (1996) Radiosurgery and fractionated radiation therapy: comparison of different techniques in an in vivo rat glioma model. J Neurosurg 84:10331038.

47. Zachenhofer I, Wolfsberger S, Aichholzer M, Bertalanffy A, Roessler K, Kitz K, Knosp E (2006) Gamma-knife radiosurgery for cranial base meningiomas: experience of tumor control, clinical course, and morbidity in a follow-up of more than 8 years. Neurosurgery 58:28-36.

48. Kreil W, Luggin J, Fuchs I, Weigl V, Eustacchio S, Papaefthymiou G (2005) Long term experience of gamma knife radiosurgery for benign skull base meningiomas. J Neurol Neurosurg Psychiatry 76:1425-1430.

49. Eustacchio S, Trummer M, Fuchs I, Schröttner O, Sutter B, Pendl G (2002) Preservation of cranial nerve function following Gamma Knife radiosurgery for benign skull base meningiomas: experience in 121 patients with follow-up of 5 to 9.8 years. Acta Neurochir Suppl 84:71-76.

50. Kondziolka D, Patel AD, Kano H, Flickinger JC, Lunsford LD (2016) Long-term outcomes after Gamma Knife radiosurgery for meningiomas. Am J Clin Oncol 39:453-457.

51. Kobayashi T, Kida Y, Mori Y (2001) Long-term results of stereotactic gamma radiosurgery of meningiomas. Surg Neurol 55:325-331. 
52. Han JH, Kim DG, Chung HT, Park CK, Paek SH, Kim CY, Jung HW (2008) Gamma knife radiosurgery for skull base meningiomas: long-term radiologic and clinical outcome. Int J Radiat Oncol Biol Phys 72:1324-1332.

53. Bria C, Wegner RE, Clump DA, Vargo JA, Mintz AH, Heron DE, Burton SA (2011) Fractionated stereotactic radiosurgery for the treatment of meningiomas. J Cancer Res Ther 7:52-57.

54. Starke RM, Przybylowski CJ, Sugoto M, Fezeu F, Awad AJ, Ding D, Nguyen JH, Sheehan JP (2015) Gamma Knife radiosurgery of large skull base meningiomas. J Neurosurg 122:363-372.

55. Iwai Y, Yamanaka K, Nakajima H (2001) Two-staged gamma knife radiosurgery for the treatment of large petroclival and cavernous sinus meningiomas. Surg Neurol 56:308-314.

56. Su CF, Liu DW, Lee CC, Chiu TL (2017) Volume-staged gamma knife surgery for the treatment of large skull base meningioma surrounding the optical apparatus: a snowmanshape design. J Chin Med Assoc 80:697-704.

57. McTyre E, Helis CA, Farris M, Wilkins L, Sloan D, Hinson WH, Bourland JD, Dezarn WA, Munley MT, Watabe K, Xing F, Laxton AW, Tatter SB, Chan MD (2017) Emerging indications for fractionated Gamma Knife radiosurgery. Neurosurgery 80:210-216.

58. Han MS, Jang WY, Moon KS, Lim SH, Kim IY, Jung TY, Jung $S$ (2017) Is fractionated Gamma Knife radiosurgery a safe and effective treatment approach for large-volume $\left(>10 \mathrm{~cm}^{3}\right)$ intracranial meningiomas? World Neurosurg 99:477-483.

59. Jung HW, Yoo H, Paek SH, Choi KS (2000) Long-term outcome and growth rate of subtotally resected petroclival meningiomas: experience with 38 cases. Neurosurgery 46:567574.

60. DiBiase SJ, Kwok Y, Yovino S, Arena C, Naqvi S, Temple R, Regine WF, Amin P, Guo C, Chin LS (2004) Factors predicting local tumor control after gamma knife stereotactic radio- surgery for benign intracranial meningiomas. Int J Radiat Oncol Biol Phys 60:1515-1519.

61. Santacroce A, Walier M, Régis J, Liščák R, Motti E, Lindquist C, Kemeny A, Kitz K, Lippitz B, Martínez Álvarez R, Pedersen PH, Yomo S, Lupidi F, Dominikus K, Blackburn P, Mindermann T, Bundschuh O, van Eck AT, Fimmers R, Horstmann GA (2012) Long-term tumor control of benign intracranial meningiomas after radiosurgery in a series of 4565 patients. Neurosurgery 70:32-39.

62. Unger KR, Lominska CE, Chanyasulkit J, Randolph-Jackson P, White RL, Aulisi E, Jacobson J, Jean W, Gagnon GJ (2012) Risk factors for posttreatment edema in patients treated with stereotactic radiosurgery for meningiomas. Neurosurgery 70:639-645.

63. Kollová A, Liscák R, Novotný J Jr, Vladyka V, Simonová G, Janousková L (2007) Gamma Knife surgery for benign meningioma. J Neurosurg 107:325-336.

64. Oermann EK, Bhandari R, Chen VJ, Lebec G, Gurka M, Lei S, Chen L, Suy S, Azumi N, Berkowitz F, Kalhorn C, McGrail K, Collins BT, Jean WC, Collins SP (2013) Five fraction imageguided radiosurgery for primary and recurrent meningiomas. Front Oncol 3:213.

65. Chang JW, Kim SH, Huh R, Park YG, Chung SS (1999) The effects of stereotactic radiosurgery on secondary facial pain. Stereotact Funct Neurosurg 72 Suppl 1:29-37.

66. Tanaka S, Pollock BE, Stafford SL, Link MJ (2013) Stereotactic radiosurgery for trigeminal pain secondary to benign skull base tumors. World Neurosurg 80:371-377.

67. Squire SE, Chan MD, Furr RM, Lowell DA, Tatter SB, Ellis TL, Bourland JD, Deguzman AF, Munley MT, Ekstrand KE, Shaw EG, McMullen KP (2012) Gamma knife radiosurgery in the treatment of tumor-related facial pain. Stereotact Funct Neurosurg 90:145-150. 